\title{
EDITORIAL
}

\section{COMPROMISSO COM A CIÊNCIA}

Edson Aparecida de Araújo Querido Oliveira ${ }^{1}$

A atual edição da Revista Brasileira de Gestão e Desenvolvimento Regional apresenta, além da publicação dos artigos submetidos em fluxo contínuo, um dossiê especial e uma seção especial. $O$ dossiê especial - 0 patrimônio territorial como referência no processo de desenvolvimento de territórios ou regiões e a seção especial com trabalhos derivados do $\mathrm{V}$ Seminário de Desenvolvimento Regional, Estado e Sociedade SEDRES, compõem parte do esforço contínuo do periódico para constituir um espaço dinâmico para a apresentação de resultados de trabalhos de pesquisa, bem como a proposição de métodos e teorias relacionadas ao desenvolvimento regional e a sua respectiva gestão.

A atenção à dinâmica investigativa e dos debates acerca do desenvolvimento é fundamental para o fortalecimento do respectivo campo de conhecimento. $O$ periódico tem aproximado pesquisadores e fomentado o debate inerente à área de investigação desde sua primeira edição, ao acompanhar o fortalecimento das pesquisas relacionadas à multidimensionalidade dos processos de dessenvolvimento. A presença dos artigos que compõem o dossiê $\mathbf{O}$ patrimônio territorial como referência no processo de desenvolvimento de territórios ou regiões possibilita aos leitores identificar à complexidade inerente às investigações da abordagem territorial do desenvolvimento em sua multidimensionalidade social, natural, produtiva, cultural, institucional e humana.

As experiências e proposições apresentadas evidenciam os desafios relacionados a um recorte fundamental do campo de conhecimento, ao identificar como o patrimônio territorial e abordagem territorial se relacionam com o processo de desenvolvimento em sua complexidade derivada dos efeitos da inserção dos territórios na divisão internacional do trabalho, com a consideração das peculiaridades locais, regionais e nacionais em sua multidimensionalidade.

Outra marca da atual edição é a seção especial V Seminário de Desenvolvimento Regional, Estado e Sociedade SEDRES, com artigos derivados do fast track do evento homonimo realizado em março de 2021 em Taubaté. O SEDRES consolidou-se como evento fundamental para área do desnevolvimento regional, ao possibilitar para investigadores de todo o país a oportunidade de debater temas fundamentais da área de conhecimento. $\mathrm{O}$ espaço de interlocução propiciado com a realização do SEDRES favorece a publicação de pesquisas e instiga ao aprimoramento das investigações, seja sob a perspectiva temática, conceitual ou metodológica. Os artigos apresentados na seção especial exemplicaficam como interdisciplinaridade e a multidiscplinaridade presentes no campo do desenvolvimento regional estimulam e favorecem a consolidação saberes fundamentais quanto à compreensão dos desafios relacionados à diversidade regional brasileira.

Além do dossiê especial e da seção especial, são publicados na atual edição artigos submetidos à avaliação em fluxo contínuo, contribuições relacionadas à intensa pesquisa e produção de conhecimento associado ao desenvolvimento regional e à sua gestão. A Revista Brasileira de

\footnotetext{
${ }^{1}$ Editor Chefe da G \& DR. Economista, Mestre em Economia pela Pontifícia Universidade Católica de São Paulo (PUCSP)Doutor em Engenharia Aeronáutica e Mecânica pelo Instituto Tecnológico de Aeronáutica (ITA). Pós-Doutor em Gestão da Inovação Tecnológica pelo Instituto Tecnológico de Aeronáutica (ITA). Coordenador Geral e Professor do |Programa de Pósgraduação em Gestão e Desenvolvimento Regional da Universidade de Taubaté (UNITAU). E-mail: edsonaaqo@gmail.com.
} 
Gestão e Desenvolvimento Regional renova, nessa edição, assim como nas anteriores, seu reiterado compromisso em ser um espaço para a apresentação de investigações relacionadas ao seu foco e escopo, bem como a pluralidade presente no campo de conhecimento.

A defesa intransigente do rigor científico quanto à pesquisa, publicação e debate de conhecimento é um compromisso do periódico, renovado nos últimos anos frente às mútiplas crises enfrentadas contemporaneamente, desde a questão sanitária deflagrada com a disseminação do COVID-19 e o negacionismo da ciência, até a redução dos investimentos por parte do Estado brasileiro em pesquisa. Constata-se, na atual edição, que as múltiplas crises representam um desafio, mas não impedem a persistência quanto a busca por respostas necessárias para a compreensão dos efeitos das assimetrias regionais presentes no território brasileiro e, desse modo, como engendrar condições adequadas para o desenvolvimento regional no Brasil.

Esta obra está licenciada com uma Licença Creative Commons Atribuição 4.0 Internacional. 